\title{
Synergistic Effects of Olanzapine and Other Antipsychotic Agents in Combination with Fluoxetine on Norepinephrine and Dopamine Release in Rat Prefrontal Cortex
}

Wei Zhang, M.D., Ph.D., Kenneth W. Perry, M.S., David T. Wong, Ph.D., Brian D. Potts, M.S., Jingqi Bao, M.S., Gary D. Tollefson, M.D., Ph.D., and Frank P. Bymaster, M.S.

To understand the mechanism of the clinical efficacy of olanzapine and fluoxetine combination therapy for treatment-resistant depression (TRD), we studied the effects of olanzapine and other antipsychotics in combination with the selective serotonin uptake inhibitors fluoxetine or sertraline on neurotransmitter release in rat prefrontal cortex (PFC) using microdialysis. The combination of olanzapine and fluoxetine produced robust, sustained increases of extracellular levels of dopamine $\left([D A]_{e x}\right)$ and norepinephrine $\left([N E]_{e x}\right)$ up to $361 \pm 28 \%$ and $272 \pm 16 \%$ of the baseline, respectively, which were significantly greater than either drug alone. This combination produced a slightly smaller increase of serotonin $\left([5-H T]_{e x}\right)$ than fluoxetine alone. The combination of clozapine or risperidone with fluoxetine produced less robust and persistent increases of $[D A]_{e x}$ and $[N E]_{e x}$. The combination of haloperidol or MDL 100907 with fluoxetine did not increase the monoamines more than fluoxetine alone. Olanzapine plus sertraline combination increased only $[D A]_{e x}$. Therefore, the large, sustained increase of $[D A]_{e x}$ $[N E]_{e x}$ and $[5-H T]_{e x}$ in PFC after olanzapine-fluoxetine treatment was unique and may contribute to the profound antidepressive effect of the olanzapine and fluoxetine therapy in TRD. [Neuropsychopharmacology 23:250-262, 2000] (C) 2000 American College of Neuropsychopharmacology. Published by Elsevier Science Inc. All rights reserved.

Hornig-Rohan 1996; Kessler et al. 1994; Nierenberg and Amsterdam 1990; Roose et al. 1986). Various pharmacologic options, such as titration to higher doses of the initial agent, a switch to an alternative agent, or augmentation (combination) therapy have been studied in the effort to achieve better therapy for treatment-resistant depressive disorder (TRD). Previous experimental research has been mostly focused on such augmentation strategies as the addition of lithium to a tricyclic antidepressant (TCA), to which a large proportion of patients still fail to respond (Nelson 1998; Thase and Rush 1995). Selective serotonin reuptake inhibitors (SSRIs), such as fluoxetine and sertraline, although having long been proved effective in the treatment of minor and major depression, are less well studied in an augmentation context. 
In a recent 8-week, double-blind clinical trial, olanzapine, a novel "atypical" antipsychotic agent effective against both positive and negative symptoms of schizophrenia (Beasley et al. 1996) as well as depressive symptoms in psychotic patients (Tollefson et al. 1998), was combined with fluoxetine therapy. The combination therapy demonstrated a significantly greater improvement on the MADRS and CGI-S, and a numeric advantage on the HAMD-21 in patients with TRD without psychotic features, than either olanzapine or fluoxetine monotherapy (Tohen et al. 1999). Moreover, this advantage was evident after the first week of treatment (Tohen et al. 1999). Thus, the combination of olanzapine and fluoxetine in this pilot study produced a rapid and dramatic result in heretofore unresponsive patients.

Olanzapine has a broad binding profile and is an antagonist at a number of neuronal receptors including dopamine (DA) $\mathrm{D}_{1}-\mathrm{D}_{5}$, serotonin (5-HT) ${ }_{2 \mathrm{~A}, \mathrm{~B}, \mathrm{C}}, \alpha_{1}$-adrenergic, histamine $\mathrm{H}_{1}$ and muscarinic $\mathrm{M}_{1-5}$ receptor subtypes both in vitro and in vivo (Bymaster et al. 1996; Schotte et al. 1996; Zhang and Bymaster 1999). In animal experiments, olanzapine robustly increased DA and norepinephrine (NE) extracellular levels ([DA $\left.]_{\mathrm{ex}},[\mathrm{NE}]_{\mathrm{ex}}\right)$ in rat medial prefrontal cortex (mPFC) (Li et al. 1998), a brain region that is crucial for cognition, affect and social behavior (Berman and Weinberger 1990; GoldmanRakic 1996). The selective serotonin reuptake inhibitor (SSRI) fluoxetine, in addition to increasing 5-HT extracellular levels $\left([5-\mathrm{HT}]_{\mathrm{ex}}\right)$, also significantly increased $[\mathrm{DA}]_{\mathrm{ex}}$ and $[\mathrm{NE}]_{\mathrm{ex}}$ in hypothalamus (Perry and Fuller 1992, 1997) and PFC (Gobert et al. 1997).

Disturbances in NE, DA, as well as 5-HT neurotransmitter system have been suggested to be involved in the pathogenesis of mood disorders including depression (Maes and Meltzer 1995; Schatzberg and Schildkraut 1995; Willner 1995). We hypothesized that the combination of olanzapine and fluoxetine would produce significant changes in extracellular levels of monoamines that may underlie the robust clinical efficacy of the combination therapy. Therefore, we studied the effects of olanzapine and fluoxetine alone and in combination on $[5-\mathrm{HT}]_{\mathrm{ex}},[\mathrm{DA}]_{\mathrm{ex}}$ and $[\mathrm{NE}]_{\mathrm{ex}}$ in rat PFC utilizing a microdialysis technique. To investigate a potential pharmacokinetic interaction, the plasma and brain levels of olanzapine and fluoxetine when administered alone or in combination were also determined in rat. In addition, to explore the possible receptor mechanisms mediating the neurochemical changes, we also examined the effects of other antipsychotics including clozapine, risperidone, haloperidol and the selective 5- $\mathrm{HT}_{2 \mathrm{~A}}$ antagonist MDL 100907 in the same experimental paradigm. Furthermore, another selective SSRI, sertraline (Heym and Koe 1988; Koe et al. 1983), was also investigated for its effect on $[5-\mathrm{HTT}]_{\mathrm{ex}},[\mathrm{DA}]_{\mathrm{ex}}$ and $[\mathrm{NE}]_{\mathrm{ex}}$ in PFC by itself and in combination with olanzapine.

\section{METHODS}

\section{Animal Surgery}

Male Sprague-Dawley rats with body weight 260-300 g (Harlan, Sprague-Dawley, Indianapolis, IN) were used in the microdialysis studies. Rats were anesthetized with chloral hydrate/pentobarbital $(170 \mathrm{mg} / \mathrm{kg}$ and 36 $\mathrm{mg} / \mathrm{kg}$ in $30 \%$ propylene glycol and $14 \%$ ethanol, respectively) on operation day to allow the implantation of dialysis probes. Loop style microdialysis probes were constructed and implanted in the rat prefrontal cortex two days prior to use according to a previously published method (Perry and Fuller 1992). Coordinates for the PFC were: A (anterior to bregma) $3.2 \mathrm{~mm}$, L (lateral from the midsagittal suture) $0.8 \mathrm{~mm}$, and V (ventral from the dura surface) $4 \mathrm{~mm}$ (Paxinos and Watson 1986). At the end of the experiments, the probe positions were histologically verified. Rats with improper probe location or monoamine baseline values were not included in the statistical analysis.

\section{Microdialysis}

On the day of the experiment, an artificial cerebrospinal fluid ( $\mathrm{pH}$ 7.4; composed of $150 \mathrm{mM} \mathrm{NaCl}, 3 \mathrm{mM} \mathrm{KCl}$, $1.7 \mathrm{mM} \mathrm{CaCl}_{2}$, and $0.9 \mathrm{mM} \mathrm{MgCl}_{2}$ ) was delivered to the probe at a flow rate of $2.0 \mu \mathrm{l} / \mathrm{min}$. Dialysate samples $(30 \mu \mathrm{l})$ were collected every 15 minutes up to 4 hours and $[5-\mathrm{HT}]_{\mathrm{ex}},[\mathrm{DA}]_{\mathrm{ex}}$ and $[\mathrm{NE}]_{\mathrm{ex}}$ were assayed on-line using HPLC with electrochemical detection according to a previously published method ( $\mathrm{Li}$ et al. 1998). The sensitivity of detection was about $3 \mathrm{fmol}$ per $30 \mu \mathrm{l} \mathrm{sam}$ ple. The effects of drugs were determined after achieving a stable baseline for at least 3 samples.

\section{Drug Treatment}

All drugs were administered in a volume of $1 \mathrm{ml} / \mathrm{kg}$ through an implanted subcutaneous (s.c.) tube to avoid handling the rats during the experiments. Antipsychotics were dissolved in $0.01 \mathrm{~N} \mathrm{HCl}$, further acidified and sonicated if necessary. The $\mathrm{pH}$ of solutions was adjusted to 4-7. SSRIs were dissolved in distilled water. Dosage of antipsychotic agents were chosen according to each drug's in vivo potencies of blocking DA $\mathrm{D}_{2}$ or $5-\mathrm{HT}_{2 \mathrm{~A}}$ receptors reported in previous publications (Li et al. 1998; Zhang and Bymaster 1999). The SSRIs were given in doses that increased [5-HT] $]_{e x}$ in previous publications (Perry and Fuller 1992, 1997; Sprouse et al. 1996). In the combination studies, antipsychotic agents were administered 30 minutes prior to SSRI injection to decrease potential pharmacokinetic interactions. Each drug or drug combination was given to 5-6 rats which received either a single drug or single drug combination. 


\section{Plasma and Brain Levels of Drugs}

For determination of plasma and brain levels of olanzapine, fluoxetine, and norfluoxetine, male Sprague-Dawley ( $n=3$ per group) weighing about $250-300$ g were administered $3 \mathrm{mg} / \mathrm{kg}$ (s.c.) olanzapine and $10 \mathrm{mg} / \mathrm{kg}$ (s.c.) fluoxetine 2 and 1.5 hours prior to euthanasia with carbon dioxide, respectively. The combination group received olanzapine and fluoxetine 2 and 1.5 hours prior to sample collection, respectively. Following anesthesia with carbon dioxide, blood samples were collected by cardiac puncture in heparinized tubes, and plasma was collected by centrifugation. Subsequently, the brain was perfused with normal saline, excised and weighed. Four milliliters of distilled water/g brain was added and the tissue was homogenized. Brain homogenates and plasma samples were then frozen in dry ice and stored at approximately $-70^{\circ} \mathrm{C}$ until analysis.

Plasma and brain samples were analyzed for fluoxetine and norfluoxetine concentrations using validated HPLC/MS/MS assays. Plasma samples were prepared for quantitation by adding potassium phosphate buffer ( $\mathrm{pH}$ 6) and internal standard to $0.5 \mathrm{ml}$ of plasma and extracting on an Isolute HCX solid phase extraction column. The samples were eluted with $2 \%$ ammonium hydroxide in methylene chloride/methanol, evaporated, and reconstituted in mobile phase (methanol/ $0.05 \%$ trifluoroacetic acid, 80/20). Brain samples were extracted in $5 \mathrm{ml}$ of $0.3 \%$ butanol in hexane following the addition of $1 \%$ diethylamine, $1 \mathrm{~N} \mathrm{NaOH}$ and internal standard to $0.5 \mathrm{ml}$ of brain homogenate. The organic layer was evaporated and reconstituted in mobile phase. The plasma and brain extracts were chomatographed by HPLC on a Waters Nova-Pak CN HP column and quantitated by MS/MS with atmospheric pressure chemical ionization.

Olanzapine plasma and brain concentrations were determined using validated HPLC/electrochemical assays. Potassium phosphate buffer $(\mathrm{pH} 6)$ and internal standard were added to $1.0 \mathrm{ml}$ of plasma. The plasma samples were loaded onto Varian Certify solid phase extraction columns and eluted with $0.5 \%$ ammonium hydroxide in ethyl acetate. The eluate was evaporated and reconstituted in mobile phase $(75 \mathrm{mM}$ phosphate buffer/methanol/acetonitrile, 45/35/20). Brain extracts were prepared by adding sodium carbonate and internal standard to 0.5 $\mathrm{ml}$ of rat brain homogenate and extracting with $5 \mathrm{ml}$ of $15 \%$ dichloromethane in cyclohexane. The organic layer was evaporated and reconstituted in mobile phase. The plasma and brain extracts were chomatographed by HPLC on a YMC Basic column and quantitated by electrochemical detection.

\section{Data Analysis}

All microdialysis data were calculated as percent change from dialysate basal concentrations with 100\% defined as the average of the final three drug preinjection values. The overall effects of each drug treatment on monoamine level changes over the 4 hour experimental period were analyzed by calculating the average percentage of the baseline. In addition, changes at the 4 hour time point were chosen to study the end result of each drug treatment. Significant differences of percentage change at each time point compared with baseline values were determined by Student's t-test for paired samples. Significant differences among the treatment groups were determined by using a one-way analysis of variance (ANOVA) followed by Student's t-test. The minimal level for statistical significance was set at $p<.05$.

\section{RESULTS}

\section{Baseline Values of Extracellular 5-HT, DA and NE in PFC}

The basal $[5-\mathrm{HT}]_{\mathrm{ex}},[\mathrm{DA}]_{\mathrm{ex}}$, and $[\mathrm{NE}]_{\mathrm{ex}}$ in PFC of the conscious freely moving rats were consistent and stable across all treatment groups $(n=13)$ and the averages were $0.19 \pm$ $0.03,0.68 \pm 0.05$, and $0.27 \pm 0.02 \mathrm{pmol} / \mathrm{ml}$ of dialysate, respectively. Vehicle treatments did not produce significant changes of $[5-\mathrm{HT}]_{\mathrm{ex}}[\mathrm{DA}]_{\mathrm{ex}}$, and $[\mathrm{NE}]_{\mathrm{ex}}$ in PFC.

\section{Effects of Olanzapine and Fluoxetine Alone and In Combination on Extracellular Monoamine Levels in PFC}

Olanzapine ( $3 \mathrm{mg} / \mathrm{kg}$, s.c.) alone did not significantly affect $[5-\mathrm{HT}]_{\mathrm{ex}}$, whereas fluoxetine $(10 \mathrm{mg} / \mathrm{kg}$, s.c.) elevated $[5-\mathrm{HT}]_{\mathrm{ex}}$ up to a peak value of $388 \pm 57 \%$ of the baseline $(p<.05)$ with an average of $368 \pm 54 \%$ of the baseline over the 4 hour period $(p<.05)$ (Figure 1A, Table $1 \mathrm{~A})$. At 4 hours after fluoxetine treatment, the increase of $[5-\mathrm{HT}]_{\mathrm{ex}}$ was sustained at $382 \pm 66 \%$ of the baseline $(p<.05)$ (Figure 1A, Table 1B). In the olanzapine plus fluoxetine treatment group, $[5-\mathrm{HT}]_{\mathrm{ex}}$ was increased up to a peak value of $338 \pm 33 \%$ at the 4 hour time point, and the average over the experimental period was $278 \pm$ $15 \%$ of the baseline (both $p<.05$ ) (Figure 1A, Tables 1A and $1 \mathrm{~B})$. The increase of $[5-\mathrm{HT}]_{\mathrm{ex}}$ in the combination treatment was not significantly different from the increase caused by fluoxetine treatment alone.

Olanzapine and fluoxetine alone both significantly increased $[\mathrm{DA}]_{\mathrm{ex}}$ up to peak values of $246 \pm 38 \%$ and $175 \pm 16 \%$ with averages of $166 \pm 17 \%$ and $150 \pm 7 \%$ of the baseline (all $p<.05$ ), respectively, over the 4 hour period (Figure 1B, Table 1A). At 4 hours after drug treatment, $[\mathrm{DA}]_{\mathrm{ex}}$ returned to baseline in the olanzapine-treated group, but remained significantly elevated at $134 \pm 4 \%$ of the baseline $(p<.05)$ in the fluoxetinetreated group (Figure 1B, Table 1B). Compared to either olanzapine or fluoxetine alone, the olanzapine plus fluoxetine treatment increased $[\mathrm{DA}]_{\mathrm{ex}}$ more robustly and 

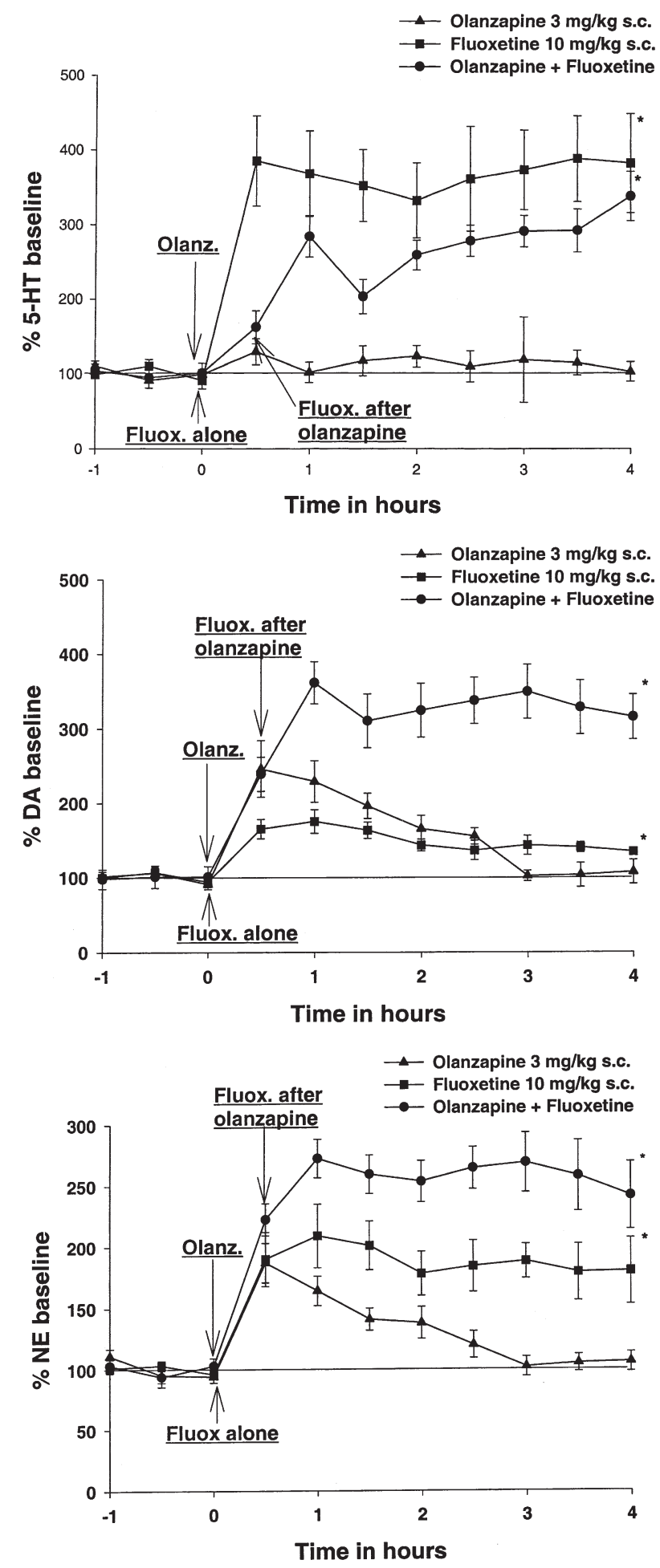

Figure 1. Effects of olanzapine ( $3 \mathrm{mg} / \mathrm{kg}$, s.c.) and fluoxetine $\left(10 \mathrm{mg} / \mathrm{kg}\right.$, s.c.) alone and in combination on $[5-\mathrm{HT}]_{\mathrm{ex}}$ $(\mathrm{A}),[\mathrm{DA}]_{\mathrm{ex}}(\mathrm{B})$, and $[\mathrm{NE}]_{\mathrm{ex}}(\mathrm{C})$ in the rat prefrontal cortex. Drugs were administered s.c. after at least three stable baseline values and the arrow indicates the time of the drug administration. Each data point represents the mean percentage of baseline of 5-6 rats and the vertical lines represent standard error of mean (SEM). ${ }^{*} p<.05$ vs. baseline at the 4 hour time point. persistently up to peak values of $361 \pm 28 \%$ with an average of $332 \pm 30 \%$ of the baseline over the treatment period (both $p<.05$ ) (Figure 1B, Table 1A). This increase of $[\mathrm{DA}]_{\mathrm{ex}}$ was sustained at $315 \pm 30 \%$ of the baseline $(p<.05)$ at the 4 hour time point by the combination treatment (Figure 1B, Table 1B).

Olanzapine and fluoxetine alone both significantly increased [NE] $]_{\mathrm{ex}}$ up to peak values of $187 \pm 16 \%$ and $209 \pm$ $26 \%$ with averages of $133 \pm 9 \%$ and $189 \pm 19 \%$ of the baseline over the 4 hour period (all $p<.05$ ), respectively (Figure 1C, Table 1A). At 4 hours after drug treatment, $[N E]_{e x}$ returned to baseline in the olanzapine-treated group, but remained elevated at $180 \pm 27 \%$ of the baseline $(p<.05)$ in the fluoxetine-treated group (Figure 1C, Table 1B). Compared to either olanzapine or fluoxetine alone, the olanzapine plus fluoxetine treatment increased $[\mathrm{NE}]_{\mathrm{ex}}$ more robustly and persistently up to a peak value of $272 \pm 16 \%$ with an average of $260 \pm 19 \%$ of the baseline over the treatment period (both $p<.05$ ) (Figure 1C, Table 1A). This increase of [NE] $]_{\mathrm{ex}}$ was sustained at $242 \pm$ $28 \%$ of the baseline $(p<.05)$ at the 4 hour time point by the combination treatment (Figure 1C, Table 1B).

\section{Effects of Clozapine Alone and in Combination with Fluoxetine on Extracellular Monoamine Levels in PFC}

Clozapine (3 $\mathrm{mg} / \mathrm{kg}$, s.c.) alone did not significantly affect $[5-\mathrm{HT}]_{\mathrm{ex}}$ over the 4 hour period (Figure 2A, Table $1 \mathrm{~A})$. In the clozapine plus fluoxetine treatment group, $[5-\mathrm{HT}]_{\mathrm{ex}}$ was elevated up to a peak value of $395 \pm 73 \%$ with an average of $364 \pm 51 \%$ of the baseline over the 4 hour period (both $p<.05$ ) (Figure 2A, Table 1A), and the level remained at $354 \pm 36 \%$ of the baseline at the 4 hour time point $(p<.05)$ (Figure 2A, Table 1B). The increase of $[5-\mathrm{HT}]_{\mathrm{ex}}$ in the combination treatment was not significantly different from fluoxetine treatment alone.

Clozapine alone significantly increased $[\mathrm{DA}]_{\text {ex }}$ up to a peak value of $236 \pm 36 \%$ with an average of $194 \pm$ $29 \%$ of the baseline over the 4 hour period (both $p<.05$ ) (Figure 2B, Table 1A). At 4 hours after clozapine treatment, $[\mathrm{DA}]_{\mathrm{ex}}$ returned to baseline (Figure 2B, Table 1B). The clozapine plus fluoxetine treatment increased $[D A]_{\text {ex }}$ up to a peak value of $361 \pm 36 \%$ with an average of $228 \pm 12 \%$ of the baseline over the treatment period, which was significantly greater than either drug alone (both $p<.05$ ) (Figure 2B, Table 1A). This increase was sustained at $134 \pm 6 \%$ of the baseline $(p<.05)$ at the 4 hour time point (Figure 2B, Table 1B).

Clozapine alone significantly increased $[\mathrm{NE}]_{\text {ex }}$ up to a peak value of $218 \pm 30 \%$ with an average of $154 \pm$ $20 \%$ of the baseline over the 4 hour period (both $p<.05$ ) (Figure 2C, Table 1A). At 4 hours after clozapine treatment, $[N E]_{\text {ex }}$ returned to baseline (Figure $2 \mathrm{C}$, Table $1 \mathrm{~B}$ ). In the clozapine plus fluoxetine treatment group, $[\mathrm{NE}]_{\mathrm{ex}}$ increased up to a peak value of $210 \pm 9 \%$ with an aver- 
Table 1A. Average Percentage of Baseline on Extracellular Levels of Monoamines by Drugs Alone and in Combination with SSRIs in Rat Prefrontal Cortex over 4 Hour Experimental Period

\begin{tabular}{|c|c|c|c|c|c|c|}
\hline \multirow[b]{2}{*}{ Drug } & \multicolumn{2}{|c|}{$5-\mathrm{HT}$} & \multicolumn{2}{|c|}{ Dopamine } & \multicolumn{2}{|c|}{ Norepinephrine } \\
\hline & Alone & + SSRI & Alone & + SSRI & Alone & + SSRI \\
\hline & & & \multicolumn{2}{|c|}{ Average $\%$ of Baseline } & & \\
\hline $\begin{array}{c}\text { Antipsychotics } \\
\text { Olanzapine* }\end{array}$ & $118 \pm 17$ & $\begin{array}{l}278 \pm 15^{* d} \\
311 \pm 43(\mathrm{~S})^{* d}\end{array}$ & $166 \pm 17^{*}$ & $\begin{array}{l}332 \pm 30^{* d s} \\
270 \pm 16(S)^{* d s}\end{array}$ & $133 \pm 9^{*}$ & $\begin{array}{l}260 \pm 19^{* d s} \\
123 \pm 7(S)^{*}\end{array}$ \\
\hline Clozapine & $106 \pm 11$ & $364 \pm 51^{* d}$ & $194 \pm 29 *$ & $228 \pm 12^{* s}$ & $154 \pm 20^{*}$ & $146 \pm 17^{*}$ \\
\hline Risperidone & $101 \pm 9$ & $406 \pm 73^{* d}$ & $134 \pm 8^{*}$ & $255 \pm 44^{* d s}$ & $159 \pm 10^{*}$ & $200 \pm 39^{*}$ \\
\hline Haloperidol & $77 \pm 6^{*}$ & $336 \pm 39^{* d}$ & $117 \pm 11$ & $153 \pm 14^{* d}$ & $106 \pm 9$ & $188 \pm 18^{* d}$ \\
\hline MDL100907 & $113 \pm 5$ & $254 \pm 31^{* d}$ & $114 \pm 11$ & $126 \pm 6^{* s}$ & $101 \pm 8$ & $143 \pm 10^{* d}$ \\
\hline \multicolumn{7}{|l|}{ SSRIs } \\
\hline Fluoxetine & $368 \pm 54^{*}$ & & $150 \pm 7^{*}$ & & $189 \pm 19^{*}$ & \\
\hline Sertraline & $432 \pm 57^{*}$ & & $117 \pm 15$ & & $120 \pm 14$ & \\
\hline
\end{tabular}

SSRI was fluoxetine unless otherwise indicated by (S) which indicates SSRI was sertraline.

Numbers are mean average $\%$ of baseline values \pm SEM.

${ }^{*} P<.05$ : Treatment is significantly different from baseline.

${ }^{d} P<.05:$ Combination treatment is significantly different from drug alone.

${ }^{s} P<.05$ : Combination treatment is significantly different from SSRI alone.

age of $146 \pm 17 \%$ of the baseline (both $p<.05$ ) (Figure $2 \mathrm{C}$, Table $1 \mathrm{~A})$, and the increase of $[\mathrm{NE}]_{\mathrm{ex}}$ returned to baseline at the 4 hour time point (Figure 2C, Table 1B). The increase of $[\mathrm{NE}]_{\mathrm{ex}}$ in the clozapine plus fluoxetine treatment group was not significantly different from either clozapine or fluoxetine treatment alone.

\section{Effects of Risperidone Alone and in Combination with Fluoxetine on Extracellular Monoamine Levels in PFC}

Risperidone (1 $\mathrm{mg} / \mathrm{kg}$, s.c.) alone did not significantly affect $[5-\mathrm{HT}]_{\mathrm{ex}}$ over the 4 hour period (Figure
3A, Table 1A). In the risperidone plus fluoxetine treatment group, $[5-\mathrm{HT}]_{\mathrm{ex}}$ was elevated up to a peak value of $474 \pm 72 \%$ at the 4 hour time point with an average of $406 \pm 73 \%$ of the baseline over the 4 hour period (both $p<.05$ ) (Figure 3A, Tables 1A and 1B). The increase of $[5-\mathrm{HT}]_{\mathrm{ex}}$ in the combination treatment was not significantly different from fluoxetine treatment alone.

Risperidone alone significantly increased $[\mathrm{DA}]_{\mathrm{ex}}$ up to a peak value of $187 \pm 15 \%$ with an average of $134 \pm 8 \%$ of the baseline over the 4 hour period (both $p<.05$ ) (Figure 3B, Table 1A). At 4 hours after risperidone treatment, $[\mathrm{DA}]_{\mathrm{ex}}$ returned to the baseline (Fig-

Table 1B. Average Percentage of Baseline on Extracellular Levels of Monoamines by Drugs Alone and in Combination with SSRIs in Rat Prefrontal Cortex at the 4 Hour Time Point $(4 \mathrm{hr})$

\begin{tabular}{|c|c|c|c|c|c|c|}
\hline \multirow[b]{2}{*}{ Drug } & \multicolumn{2}{|c|}{ 5-HT } & \multicolumn{2}{|c|}{ Dopamine } & \multicolumn{2}{|c|}{ Norepinephrine } \\
\hline & Alone & + SSRI & Alone & + SSRI & Alone & + SSRI \\
\hline & & & \multicolumn{2}{|c|}{$\%$ baseline at $4 \mathrm{hr}$} & & \\
\hline \multirow{2}{*}{$\begin{array}{c}\text { Antipsychotics } \\
\text { Olanzapine }\end{array}$} & & & & & & \\
\hline & $103 \pm 13$ & $\begin{array}{l}338 \pm 33^{* d} \\
344 \pm 53(\mathrm{~S})^{* d}\end{array}$ & $107 \pm 16$ & $\begin{array}{l}315 \pm 30^{* d s} \\
199 \pm 22(S)^{* d s}\end{array}$ & $106 \pm 8$ & $\begin{array}{l}242 \pm 28^{* d} \\
104 \pm 10(\mathrm{~S})\end{array}$ \\
\hline Clozapine & $126 \pm 25$ & $354 \pm 36^{* d}$ & $112 \pm 16$ & $134 \pm 6^{*}$ & $97 \pm 14$ & $109 \pm 17$ \\
\hline Risperidone & $76 \pm 8$ & $474 \pm 72^{* d}$ & $94 \pm 3$ & $210 \pm 26^{* d s}$ & $107 \pm 6$ & $166 \pm 33$ \\
\hline Haloperidol & $75 \pm 10$ & $360 \pm 53^{* d}$ & $119 \pm 20$ & $154 \pm 16^{*}$ & $101 \pm 14$ & $193 \pm 16^{* d}$ \\
\hline MDL100907 & $96 \pm 8$ & $209 \pm 27^{* d s}$ & $106 \pm 14$ & $99 \pm 6^{s}$ & $91 \pm 12$ & $121 \pm 13$ \\
\hline \multicolumn{7}{|l|}{ SSRIs } \\
\hline Fluoxetine & $382 \pm 66^{*}$ & & $134 \pm 4^{*}$ & & $180 \pm 27^{*}$ & \\
\hline Sertraline & $455 \pm 62^{*}$ & & $107 \pm 21$ & & $103 \pm 2$ & \\
\hline
\end{tabular}

SSRI was fluoxetine unless otherwise indicated by (S) which indicates SSRI was sertraline.

Numbers are mean average $\%$ of baseline values \pm SEM.

${ }^{*} P<.05$ : Treatment is significantly different from baseline.

${ }^{d} P<.05$ : Combination treatment is significantly different from drug alone.

${ }^{s} P<.05$ : Combination treatment is significantly different from SSRI alone. 

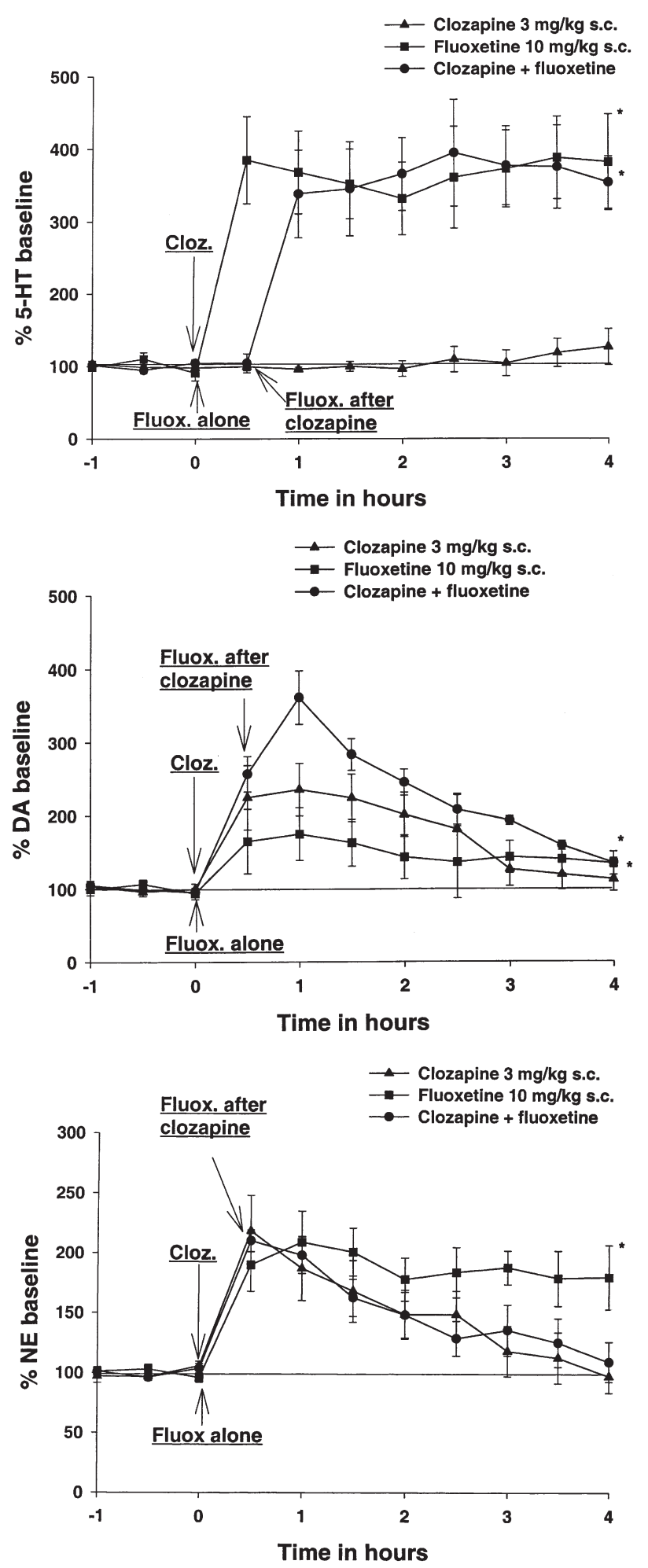

Figure 2. Effects of clozapine ( $3 \mathrm{mg} / \mathrm{kg}$, s.c.) and fluoxetine $\left(10 \mathrm{mg} / \mathrm{kg}\right.$, s.c.) alone and in combination on $[5-\mathrm{HT}]_{\mathrm{ex}}(\mathrm{A})$, $[D A]_{e x}(B)$, and $[N E]_{e x}(C)$ in the rat prefrontal cortex. Drugs were administered s.c. after at least three stable baseline values and the arrow indicates the time of the drug administration. Each data point represents the mean percentage of baseline of 5-6 rats and the vertical lines represent SEM. ${ }^{*} p<.05$ vs. baseline at the 4 hour time point. ure $3 \mathrm{~B}$, Table $1 \mathrm{~B})$. The risperidone plus fluoxetine treatment increased $[\mathrm{DA}]_{\mathrm{ex}}$ up to a peak value of $305 \pm$ $43 \%$ with an average of $255 \pm 44 \%$ of the baseline over the treatment period (both $p<.05$ ) (Figure 3B, Table $1 \mathrm{~A})$. The average increase of $[\mathrm{DA}]_{\text {ex }}$ produced by the combination was significantly different from either risperidone or fluoxetine treatment alone $(p<$ $.05)$. The level of $[\mathrm{DA}]_{\mathrm{ex}}$ was sustained at $210 \pm 26 \%$ of the baseline $(p<.05)$ at the 4 hour time point (Figure 3B, Table 1B).

Risperidone alone significantly increased $[\mathrm{NE}]_{\mathrm{ex}}$ up to a peak value of $243 \pm 22 \%$ with an average of $159 \pm$ $10 \%$ of the baseline over the 4 hour period (both $p<.05$ ) (Figure 3C, Table 1A). At 4 hours after drug treatment, $[\mathrm{NE}]_{\mathrm{ex}}$ returned to the baseline (Figure $3 \mathrm{C}$, Table 1B). In the risperidone plus fluoxetine treatment group, $[\mathrm{NE}]_{\mathrm{ex}}$ increased up to a peak value of $227 \pm 46 \%$ with an average of $200 \pm 39 \%$ of the baseline over the treatment period (both $p<.05$ ) (Figure 3C, Table 1A). The level of $[\mathrm{NE}]_{\mathrm{ex}}$ was $166 \pm 33 \%$ at the 4 hour time point, which was not significantly different from the baseline (Figure $3 \mathrm{C}$, Table $1 \mathrm{~B})$. The increase of $[\mathrm{NE}]_{\mathrm{ex}}$ in the risperidone plus fluoxetine treatment group was not significantly different from either risperidone or fluoxetine treatment alone.

\section{Effects of Haloperidol Alone and in Combination with Fluoxetine on Extracellular Monoamine Levels in PFC}

Haloperidol (1 $\mathrm{mg} / \mathrm{kg}$, s.c.) alone did not significantly increase $[5-\mathrm{HT}]_{\mathrm{ex}},[\mathrm{DA}]_{\mathrm{ex}}$ or $[\mathrm{NE}]_{\mathrm{ex}}$ over the 4 hour period. The increases of $[5-\mathrm{HT}]_{\mathrm{ex}},[\mathrm{DA}]_{\mathrm{ex}}$, or $[\mathrm{NE}]_{\mathrm{ex}}$ in the haloperidol plus fluoxetine treatment group were not significantly different from fluoxetine treatment alone (Figures 4A, 4B, and 4C, Tables 1A and 1B).

\section{Effects of MDL 100907 Alone and in Combination with Fluoxetine on Extracellular Monoamine Levels in PFC}

MDL 100907 (1 mg/kg, s.c.) alone did not significantly affect $[5-\mathrm{HT}]_{\mathrm{ex}},[\mathrm{DA}]_{\mathrm{ex}}$, or $[\mathrm{NE}]_{\mathrm{ex}}$ over the 4 hour period (Figures 5A, 5B, and 5C, Tables $1 \mathrm{~A}$ and $1 \mathrm{~B}$ ). In the MDL 100907 plus fluoxetine treatment group, the average levels of $[5-\mathrm{HT}]_{\mathrm{ex}},[\mathrm{DA}]_{\mathrm{ex}}$, and $[\mathrm{NE}]_{\mathrm{ex}}$ over the 4 hour period were $254 \pm 31 \%, 126 \pm 6 \%$, and $143 \pm 10 \%$ of their baseline, respectively (all $p<.05$ ). At the 4 hour time point, only [5-HT] $]_{\mathrm{ex}}$ remained elevated at $209 \pm 27 \%$ of the baseline, both $[\mathrm{DA}]_{\mathrm{ex}}$ and $[\mathrm{NE}]_{\mathrm{ex}}$ returned to baseline (Figures 5A, 5B, and 5C, Tables $1 \mathrm{~A}$ and $1 \mathrm{~B}$ ). The monoamine extracellular levels after administration of MDL 100907 plus fluoxetine were lower than those produced by fluoxetine treatment alone. 

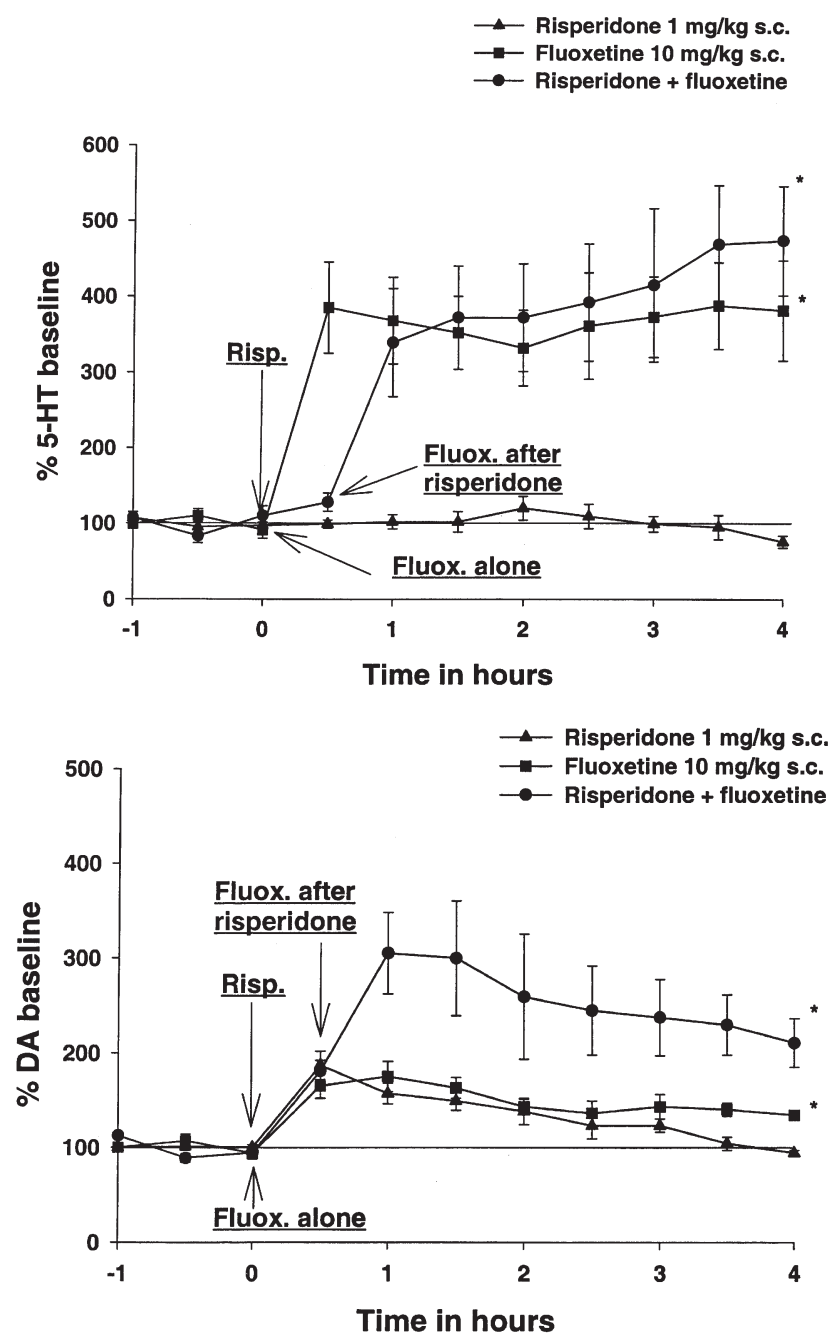

$\_$Risperidone $1 \mathrm{mg} / \mathrm{kg}$ s.c. $\rightarrow-$ Fluoxetine $10 \mathrm{mg} / \mathrm{kg}$ s.c. $\longrightarrow$ Risperidone + fluoxetine

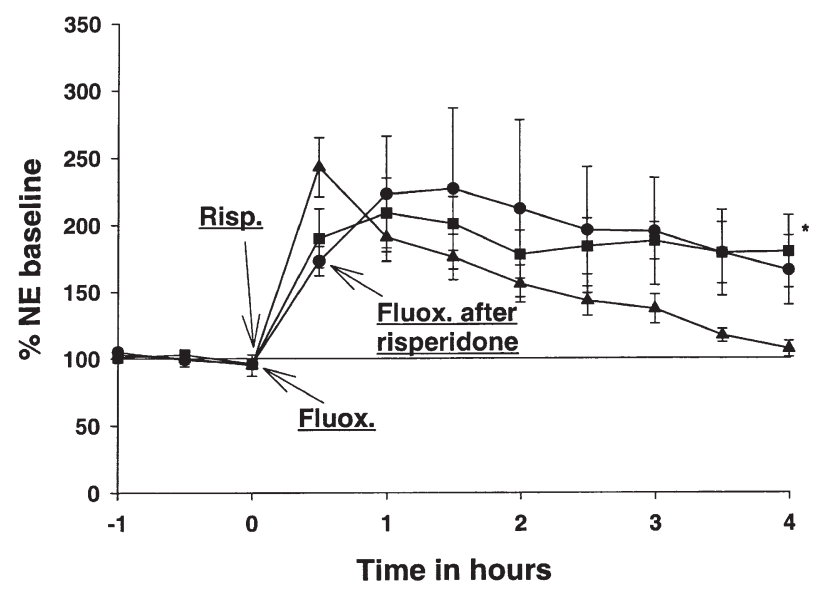

Figure 3. Effects of risperidone ( $1 \mathrm{mg} / \mathrm{kg}$, s.c.) and fluoxetine $\left(10 \mathrm{mg} / \mathrm{kg}\right.$, s.c.) alone and in combination on $[5-\mathrm{HT}]_{\mathrm{ex}}$ $(\mathrm{A}),[\mathrm{DA}]_{\mathrm{ex}}(\mathrm{B})$, and $[\mathrm{NE}]_{\mathrm{ex}}(\mathrm{C})$ in the rat prefrontal cortex. Drugs were administered s.c. after at least three stable baseline values and the arrow indicates the time of the drug

\section{Effects of Sertraline Alone and in Combination with Olanzapine on Extracellular Monoamine Levels in PFC}

Sertraline $\left(10 \mathrm{mg} / \mathrm{kg}\right.$, s.c.) alone increased $[5-\mathrm{HT}]_{\text {ex }}$ up to a peak value of $462 \pm 66 \%(p<.05)$ with an average of $432 \pm 57 \%$ of the baseline over the 4 hour period ( $p<$ .05) (Figure 6A, Table 1A). At 4 hours after sertraline treatment, the level of [5-HT] $]_{\text {ex }}$ was sustained at $455 \pm$ $62 \%$ of the baseline $(p<.05)$ (Figure 6A, Table 1B). In the olanzapine plus sertraline treatment group, $[5-\mathrm{HT}]_{\mathrm{ex}}$ increased up to a peak value of $344 \pm 53 \%$ of the baseline at 4 hour time point with an average of $311 \pm 43 \%$ of the baseline over the 4 hour period (both $p<.05$ ) (Fig. 6A, Tables 1A and 1B). The increase of $[5-\mathrm{HT}]_{\mathrm{ex}}$ in the combination treatment was not significantly different from sertraline treatment alone, although it was consistently lower in magnitude.

Sertraline alone only transiently increased $[\mathrm{DA}]_{\mathrm{ex}}$ up to a peak value of $136 \pm 13 \%$ of the baseline $(p<.05)$ with an average not significantly different from the baseline (Figure 6B, Table 1A). At 4 hours after drug treatment, $[\mathrm{DA}]_{\mathrm{ex}}$ returned to baseline (Figure $6 \mathrm{~B}$, Table 1B). The olanzapine plus sertraline treatment elevated [DA $]_{\text {ex }}$ to a peak value of $369 \pm 45 \%$ with an average of $270 \pm 16 \%$ over the 4 hour period. The $[\mathrm{DA}]_{\text {ex }}$ level remained at $199 \pm 22 \%$ of the baseline at the 4 hour time point (all $p<.05)$. The increase of $[\mathrm{DA}]_{\mathrm{ex}}$ was significantly higher than those in either the olanzapine or sertraline treatment alone (both $p<.05$ ).

Sertraline alone only transiently increased $[\mathrm{NE}]_{\mathrm{ex}}$ up to a peak value of $124 \pm 7 \%$ of the baseline $(p<.05)$ with an average not significantly different from the baseline (Figure 6C, Table 1A). At 4 hours after sertraline treatment, $[\mathrm{NE}]_{\text {ex }}$ returned to the baseline (Figure 6C, Table 1B). The olanzapine plus sertraline treatment elevated $[\mathrm{NE}]_{\mathrm{ex}}$ to a peak value of $198 \pm 12 \%$ with an average of $123 \pm 7 \%$ of the baseline (both $p<.05$ ). The increase of $[\mathrm{NE}]_{\mathrm{ex}}$ returned to baseline at the 4 hour time point. These changes of $[\mathrm{NE}]_{\mathrm{ex}}$ were not significantly different from either olanzapine or sertraline alone treatment groups.

\section{Pharmacokinetic Interaction}

At 2 hour after initial drug treatment, brain levels of olanzapine were $1008 \pm 103 \mathrm{ng} / \mathrm{gm}$ in the olanzapinetreated rats and $1065 \pm 90 \mathrm{ng} / \mathrm{gm}$ in the olanzapine plus fluoxetine-treated rats (Table 2). Brain levels of fluoxetine 1.5 hour after treatment were $8118 \pm 686 \mathrm{ng} /$

administration. Each data point represents the mean percentage of baseline of 5-6 rats and the vertical lines represent SEM. ${ }^{*} p<.05$ vs. baseline at the 4 hour time point. 

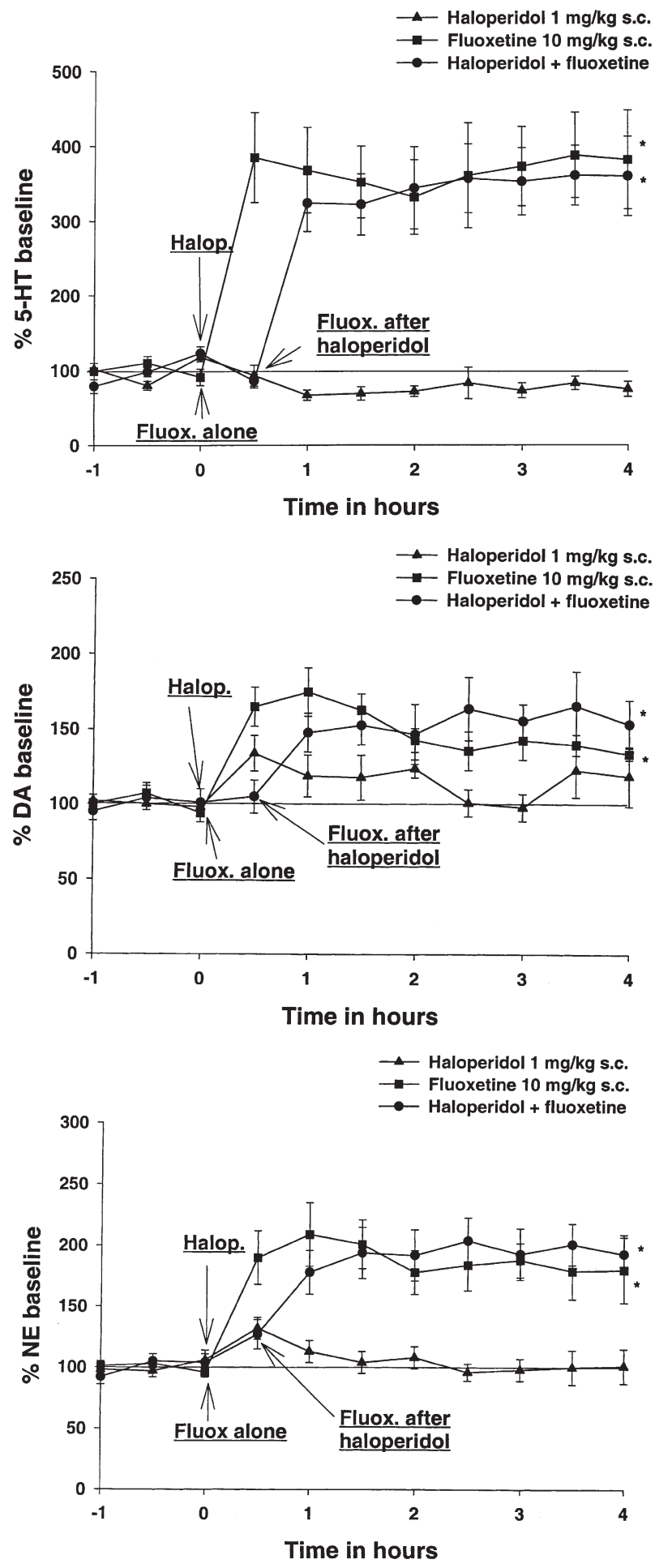

Figure 4. Effects of haloperidol (1 $\mathrm{mg} / \mathrm{kg}$, s.c.) and fluoxetine $\left(10 \mathrm{mg} / \mathrm{kg}\right.$, s.c.) alone and in combination on $[5-\mathrm{HT}]_{\mathrm{ex}}$ $(\mathrm{A}),[\mathrm{DA}]_{\mathrm{ex}}(\mathrm{B})$, and $[\mathrm{NE}]_{\mathrm{ex}}(\mathrm{C})$ in the rat prefrontal cortex. Drugs were administered s.c. after at least three stable baseline values and the arrow indicates the time of the drug administration. Each data point represents the mean percentage of baseline of 5-6 rats and the vertical lines represent SEM. ${ }^{*} p<.05$ vs. baseline at the 4 hour time point.
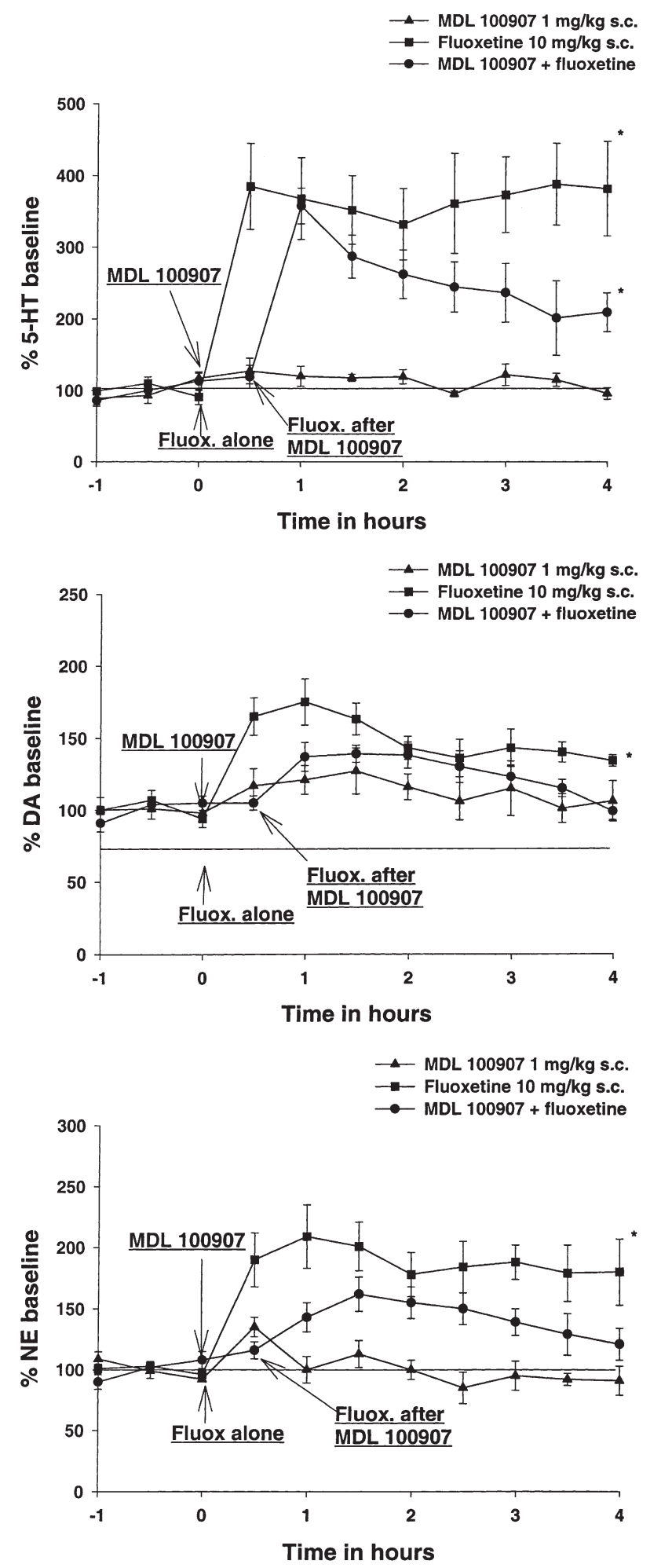

Figure 5. Effects of MDL 100907 (1 mg/ $\mathrm{kg}$, s.c.) and fluoxetine $\left(10 \mathrm{mg} / \mathrm{kg}\right.$, s.c.) alone and in combination on $[5-\mathrm{HT}]_{\mathrm{ex}}$ $(A),[D A]_{e x}(B)$, and $[N E]_{e x}(C)$ in the rat prefrontal cortex. Drugs were administered s.c. after at least three stable baseline values and the arrow indicates the time of the drug administration. Each data point represents the mean percentage of baseline of 5-6 rats and the vertical lines represent SEM. ${ }^{*}<.05$ vs. baseline at the 4 hour time point. 

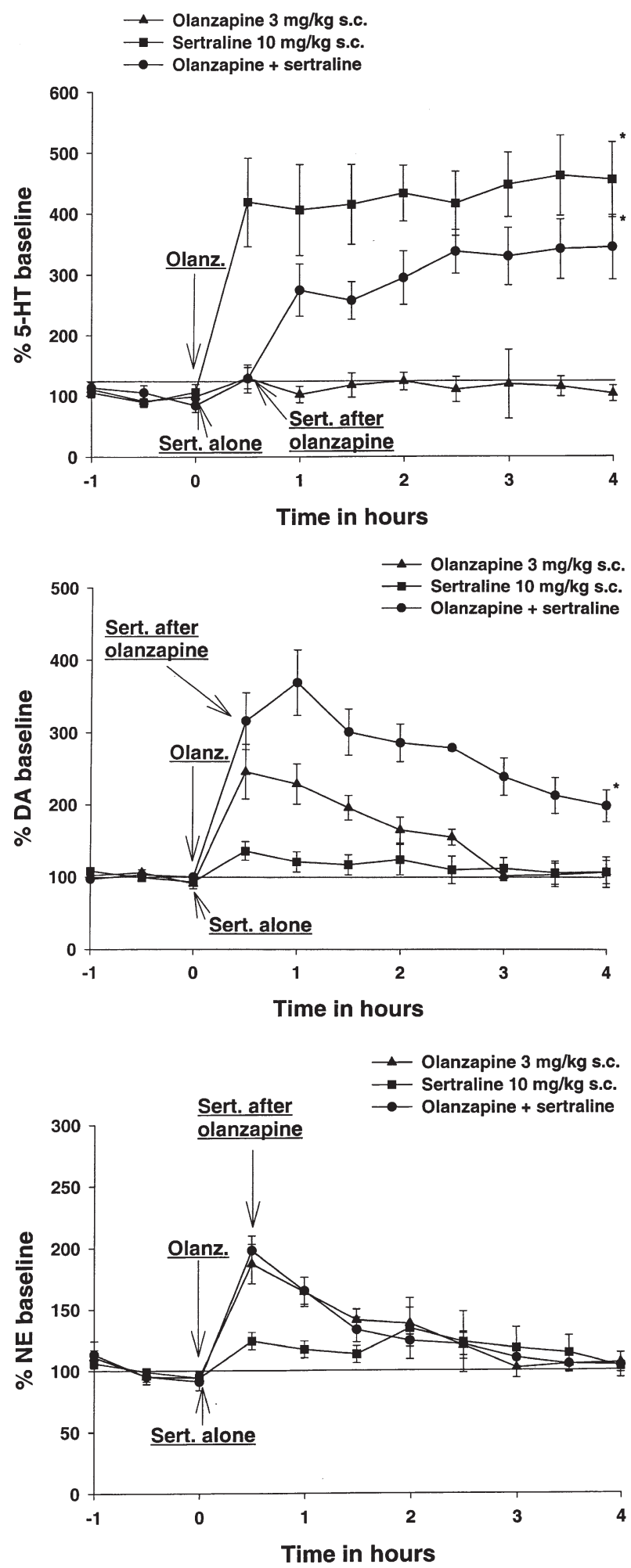

Figure 6. Effects of olanzapine ( $3 \mathrm{mg} / \mathrm{kg}$, s.c.) and sertraline $\left(10 \mathrm{mg} / \mathrm{kg}\right.$, s.c.) alone and in combination on $[5-\mathrm{HT}]_{\mathrm{ex}}$ $(\mathrm{A}),[\mathrm{DA}]_{\mathrm{ex}}(\mathrm{B})$, and $[\mathrm{NE}]_{\mathrm{ex}}(\mathrm{C})$ in the rat prefrontal cortex. Drugs were administered s.c. after at least three stable baseline values and the arrow indicates the time of the drug administration. Each data point represents the mean percentage of baseline of 5-6 rats and the vertical lines represent SEM. ${ }^{*} p<.05$ vs. baseline at the 4 hour time point.
Table 2. Brain and Plasma Levels of Olanzapine, Fluoxetine and Metabolite Norfluoxetine after Administration of Olanzapine ( $3 \mathrm{mg} / \mathrm{kg}$, s.c.) and Fluoxetine (10 mg/kg, s.c.) Alone or in Combination

\begin{tabular}{|c|c|c|c|}
\hline Drug Measured & $\begin{array}{l}\text { Olanzapine } \\
3 \mathrm{mg} / \mathrm{kg} \text {, s.c. }\end{array}$ & $\begin{array}{c}\text { Fluoxetine } \\
10 \mathrm{mg} / \mathrm{kg} \text {, s.c. }\end{array}$ & $\begin{array}{c}\text { Olanzapine }+ \\
\text { Fluoxetine }\end{array}$ \\
\hline & & $\begin{array}{l}\text { Plasma, ng/ml } \\
\text { @ } 2 \text { hours* }\end{array}$ & \\
\hline Olanzapine & $151 \pm 22$ & - & $219 \pm 36$ \\
\hline Fluoxetine & - & $261 \pm 20$ & $391 \pm 72$ \\
\hline Norfluoxetine & - & $\begin{array}{c}173 \pm 10 \\
\text { Brain, ng/gm } \\
\text { @ } 2 \text { hours* }\end{array}$ & $148 \pm 21$ \\
\hline Olanzapine & $1008 \pm 103$ & - & $1065 \pm 90$ \\
\hline Fluoxetine & - & $8118 \pm 686$ & $9390 \pm 607$ \\
\hline Norfluoxetine & - & $1823 \pm 62$ & $1318 \pm 103$ \\
\hline
\end{tabular}

${ }^{*}$ Fluoxetine was given 0.5 hour after olanzapine or vehicle and 1.5 hour prior to measurement. Drug levels were measured in groups of three rats as described in Methods.

gm in the fluoxetine-treated rats and $9390 \pm 607 \mathrm{ng} / \mathrm{gm}$ in the olanzapine plus fluoxetine-treated rats. The brain levels of the active fluoxetine metabolite norfluoxetine were $1823 \pm 62 \mathrm{ng} / \mathrm{gm}$ in the fluoxetine-treated rats and $1318 \pm 103 \mathrm{ng} / \mathrm{gm}$ in the olanzapine plus fluoxetine-treated rats. Thus, brain levels of olanzapine in the olanzapine plus fluoxetine-treated rats were not significantly different from the olanzapine alone-treated group. In addition, the sum of fluoxetine and norfluoxetine concentrations in olanzapine plus fluoxetinetreated rats was not significantly different from that of the fluoxetine alone-treated group. The plasma levels of olanzapine, fluoxetine, and norfluoxetine from the combination treatment were not significantly different from treatment of either drug alone.

\section{DISCUSSION}

In our present study, we investigated the effects of systemic administration of a number of antipsychotic agents and two SSRIs alone and the combination of an antipsychotic agent plus SSRI on extracelluar levels of monoamines in rat prefrontal cortex. The doses of the antipsychotics and SSRIs were carefully chosen based on previously published studies. Olanzapine and clozapine doses ( $3 \mathrm{mg} / \mathrm{kg}$, sc) were chosen to produce nearly equal increases of $[\mathrm{DA}]_{\mathrm{ex}}$ and $[\mathrm{NE}]_{\mathrm{ex}}$ in PFC, but were not peak doses in order to avoid potential ceiling effects (Li et al. 1998). The dose of haloperidol (1 mg/ $\mathrm{kg}$, s.c.), MDL 100907 (1 mg/kg, s.c.), and risperidone (1 mg/kg, s.c.) were chosen based on previous publications (Hertel et al. 1996; Kuroki et al. 1999; Li et al. 1998; Schmidt and Fadayel 1995; Volonte et al. 1997). The dose of fluoxetine $(10 \mathrm{mg} / \mathrm{kg}$, s.c.) has been previously used in our laboratory and produced the maximal increase in $[5-\mathrm{HT}]_{\mathrm{ex}}$ 
(Perry and Fuller 1992, 1997). The dose of sertraline (10 $\mathrm{mg} / \mathrm{kg}$, s.c.) was chosen from published studies and is an effective dose for producing increases in $[5-\mathrm{HT}]_{\mathrm{ex}}$ (Sprouse et al. 1996).

Consistent with previous findings (Hertel et al. 1996; Kuroki et al. 1999; Li et al. 1998; Volonte et al. 1997), atypical antipsychotic agents including olanzapine, clozapine, and risperidone alone increased both $[\mathrm{DA}]_{\mathrm{ex}}$ and $[\mathrm{NE}]_{\mathrm{ex}}$ to varying degrees in rat cortical areas. Olanzapine, clozapine, and risperidone did not show appreciable changes on $[5-\mathrm{HT}]_{\mathrm{ex}}$ in $\mathrm{PFC}$ although risperidone was reported to increase $[5-\mathrm{HT}]_{\mathrm{ex}}$ in the rat medial PFC (Hertel et al. 1997; Ichikawa et al. 1998). Haloperidol, a typical antipsychotic with mainly $\mathrm{D}_{2} / \mathrm{D}_{3} / \mathrm{D}_{4}$ antagonistic properties (Bymaster et al. 1997) and MDL 100907, a selective $5-\mathrm{HT}_{2 \mathrm{~A}}$ antagonist (Sorensen et al. 1993) did not significantly change any of these monoamine levels.

Although the present data on haloperidol, in general, agree with several previous studies, one study reported increases of both $[\mathrm{DA}]_{\mathrm{ex}}$ and $[\mathrm{NE}]_{\mathrm{ex}}$ to about $180 \%$ of the baseline induced by a dose of $800 \mathrm{nmol} / \mathrm{kg}$ (equivalent to $0.3 \mathrm{mg} / \mathrm{kg}$, s.c.) of haloperidol (Westerink et al. 1998). However, several other studies reported no changes on either $[\mathrm{DA}]_{\mathrm{ex}}$ or $[\mathrm{NE}]_{\mathrm{ex}}$ induced by haloperidol (Kuroki et al. 1999; Li et al. 1998; Volonte et al. 1997). One study also reported an increase of $[D A]_{\text {ex }}$ up to approximately $300 \%$ of the baseline by $1 \mathrm{mg} / \mathrm{kg}$ of MDL 100907 (Schmidt and Fadayel 1995). The reason for these differences are unclear, but factors such as dissimilarities in the brain region of interest, drug dosage, types of dialysis probe, as well as "arousal" or "stress" produced by animal handling may contribute to the disparities in results. In the present study, drugs were administered remotely via a previously implanted s.c. cannula to avoid alteration of monoamine levels due to stress from handling. Overall, our results are in agreement with the majority of previous studies.

The two SSRIs fluoxetine and sertraline robustly increased $[5-\mathrm{HT}]_{\mathrm{ex}}$ in PFC, consistent with a number of previous studies on brain regions such as striatum and hypothalamus (Dreshfield et al. 1996; Perry and Fuller 1992; Sprouse et al. 1996). However, while fluoxetine treatment resulted in a sustained elevation of $[\mathrm{NE}]_{\mathrm{ex}}$ and $[D A]_{e x}$ in PFC, consistent with previous reports in hypothalamus (Perry and Fuller 1997), neither $[N E]_{\mathrm{ex}}$ nor $[D A]_{\text {ex }}$ were significantly changed by sertraline treatment, consistent with another study which measured only $[\mathrm{NE}]_{\mathrm{ex}}$ (Thomas et al. 1998).

The combination of olanzapine and fluoxetine produced robust and remarkably sustained increases of $[\mathrm{DA}]_{\mathrm{ex}}$ and $[\mathrm{NE}]_{\mathrm{ex}}$ in PFC, which were significantly greater than either drug alone. The effect of this combination did not alter significantly alter $[5-\mathrm{HT}]_{\mathrm{ex}}$ compared to fluoxetine alone. Clozapine plus fluoxetine produced a robust increase of $[\mathrm{DA}]_{\mathrm{ex}}$, but the effect was not sustained. Compared to fluoxetine alone, the com- bination of clozapine and fluoxetine produced neither a peak nor a sustained increase of $[\mathrm{NE}]_{\mathrm{ex}}$ and the increase of [5-HT] $]_{\mathrm{ex}}$ was also not significantly different from fluoxetine alone. Risperidone in combination with fluoxetine produced a robust and significant increase of $[\mathrm{DA}]_{\mathrm{ex}}$, however, the effect on $[\mathrm{NE}]_{\mathrm{ex}}$ and $[5-\mathrm{HT}]_{\mathrm{ex}}$ was not significantly different from the effect of fluoxetine alone. Neither the typical antipsychotic haloperidol nor MDL 100907 in combination with fluoxetine increased $[\mathrm{DA}]_{\mathrm{ex}},[\mathrm{NE}]_{\mathrm{ex}}$, and $[5-\mathrm{HT}]_{\mathrm{ex}}$ more than fluoxetine alone. The olanzapine plus sertraline combination did not increase $[\mathrm{NE}]_{\mathrm{ex}}$ more than that of olanzapine alone. However, the olanzapine and sertraline combination produced a sustained increase of $[\mathrm{DA}]_{\mathrm{ex}}$, although not to the extent of the olanzapine and fluoxetine combination. Thus, atypical antipsychotic drugs and especially olanzapine, when in combination with fluoxetine produced a robust increase in $[\mathrm{DA}]_{\mathrm{ex}}$ and $[\mathrm{NE}]_{\mathrm{ex}}$, and the effect of fluoxetine on $[5-\mathrm{HTT}]_{\mathrm{ex}}$ was also sustained.

The olanzapine and fluoxetine combination treatment produced similar marked increases of $[\mathrm{DA}]_{\mathrm{ex}}$ $[\mathrm{NE}]_{\mathrm{ex}}$ at the 2 hour time point (equivalent to 2 hours after olanzapine and 1.5 hours after fluoxetine administration) compared to those of the 4 hour time point. Our pharmacokinetic data showed that at 2 hours after olanzapine and 1.5 hours after fluoxetine drug administration, neither olanzapine, fluoxetine, nor the active fluoxetine metabolite norfluoxetine levels in brain were significantly higher in the combination treatment group than either drug alone treatment. Although the brain level of fluoxetine plus its active metabolite norfluoxetine was increased by $7 \%$ in the combined treatment with olanzapine and fluoxetine, this small increase is unlikely to explain the robust increases of $[D A]_{e x}$ and $[\mathrm{NE}]_{\mathrm{ex}}$. Therefore, the robust increases in NE and DA that we observed in the combination treatment are more likely due to neurochemical mechanisms than a pharmacokinetic phenomenon.

Although we do not know the exact mechanism of the unique robust and persistent increase of $[D A]_{e x}$ and $[\mathrm{NE}]_{\text {ex }}$ observed in the olanzapine plus fluoxetine combination treatment, several postulations are attempted here. Fluoxetine, olanzapine, and risperidone have relatively low affinity for $5-\mathrm{HT}_{1 \mathrm{~A}}$ receptors indicating that increases in catecholamines are probably not mediated by interaction with that receptor (Bymaster et al. 1996; Wong et al. 1995). Since haloperidol, the typical antipsychotic with mainly $D_{2} / D_{3} / D_{4}$ antagonistic properties, or the selective 5- $\mathrm{HT}_{2 \mathrm{~A}}$ antagonist MDL $100907 \mathrm{did}$ not enhance any of fluoxetine's effect on monoamine release, the augmentation is likely not mediated by $\mathrm{D}_{2}$ or $5-\mathrm{HT}_{2 \mathrm{~A}}$ receptors alone.

Atypical antipsychotics such as olanzapine, clozapine, and risperidone are similar in that they are multireceptorial agents and have relatively high affinities for a number of receptor subtypes, yet their respective re- 
ceptor binding profiles are somewhat different (Bymaster et al. 1996). For example, both olanzapine and clozapine, but not risperidone have relatively high affinities for the $5-\mathrm{HT}_{2 \mathrm{C}}$ receptor. On the other hand, olanzapine has higher affinity for $\alpha_{1}$ - than $\alpha_{2}$-adrenergic receptors whereas clozapine and risperidone share high affinities for both $\alpha_{1}$ - and $\alpha_{2}$-adrenergic receptors (Bymaster et al. 1996). It is therefore plausible that the maximal augmentation with olanzapine plus fluoxetine treatment is mediated by either $5-\mathrm{HT}_{2 \mathrm{C}}$ or $\alpha_{1}$-adrenergic receptors. However, haloperidol has relatively high affinity for $\alpha_{1}$ adrenergic receptors (Bymaster et al. 1996) and did not augment catecholamine release.

Our study is the first to investigate changes on monoamine release in PFC using an antipsychotic plus SSRI regimen, however, previous studies applying receptor specific drugs have provided useful clues to the mechanism that we are seeking. For example, the $5-\mathrm{HT}_{2 \mathrm{C}}$ receptor agonist Ro 60-0175 markedly suppressed dialysate levels of $[\mathrm{DA}]_{\mathrm{ex}}$ and $[\mathrm{NE}]_{\mathrm{ex}}$ in frontal cortex, whereas the selective $5-\mathrm{HT}_{2 \mathrm{C}}$ antagonist SB-242084 markedly increased $[\mathrm{DA}]_{\mathrm{ex}}$ and $[\mathrm{NE}]_{\mathrm{ex}}$ (Millan et al. 1998). These data suggest that $5-\mathrm{HT}_{2 \mathrm{C}}$ receptors exert a tonic, inhibitory influence on frontocortical dopaminergic and adrenergic transmission, possibly via their excitatory effects on GABAergic interneurons (Millan et al. 1998; Pessia et al. 1994). When in combination with fluoxetine, the $5-\mathrm{HT}_{2 \mathrm{C}}$ antagonistic property of olanzapine could facilitate the persistent and robust effect on $[D A]_{\mathrm{ex}}$ and $[\mathrm{NE}]_{\mathrm{ex}}$ release in PFC. It is also possible that other receptors than just $5-\mathrm{HT}_{2 \mathrm{C}}$ and $\alpha_{1}$-adrenergic receptors are involved in the augmentation, since olanzapine has such a rich binding profile. A subtle combination of different affinities for a number of receptors could result in the unique, persistent and robust effects produced by the olanzapine and fluoxetine combination treatment.

From a different point of view, some unique features of the pharmacology of fluoxetine could also contribute to the superior effects of the olanzapine and fluoxetine combination treatment. Although both fluoxetine and sertraline presumably exert antidepressant effects by increasing brain 5-HT levels as a result of blocking serotonin reuptake (Heym and Koe 1988; Koe et al. 1983; Wong et al. 1983), fluoxetine but not sertraline, elevated both $[\mathrm{DA}]_{\mathrm{ex}}$ and $[\mathrm{NE}]_{\mathrm{ex}}$ in PFC. The increases of $[\mathrm{DA}]_{\mathrm{ex}}$ and $[\mathrm{NE}]_{\text {ex }}$ by fluoxetine were also seen in hypothalamus, another brain region of relevance in depression, as reported by previous studies (Perry and Fuller 1992, 1997). The olanzapine and fluoxetine combination treatment greatly increased both $[\mathrm{DA}]_{\mathrm{ex}}$ and $[\mathrm{NE}]_{\mathrm{ex}}$, even at 4 hours after the initial drug treatment. In contrast, when combined with olanzapine, sertraline only significantly increased $[\mathrm{DA}]_{\mathrm{ex}}$ more than either drug alone and the effect on $[\mathrm{DA}]_{\mathrm{ex}}$ was much smaller than the combination of olanzapine and fluoxetine. This in part suggests that the increase of [5-HT] $]_{\mathrm{ex}}$ may be relevant to the augmentation of $[\mathrm{DA}]_{\mathrm{ex}}$ in the combination treatment, whereas the increase of [NE] involves an additional mechanism. Interestingly, fluoxetine also has a relatively high affinity for $5-\mathrm{HT}_{2 \mathrm{C}}$ receptors (Wong et al. 1991), a feature not shared by other SSRIs including sertraline. In clonal cell lines transfected with $5-\mathrm{HT}_{2 \mathrm{C}}$ receptors and in rat choroid plexus, fluoxetine behaved as an antagonist (Palvimaki et al. 1996). All these data are consistent with our above postulation of an involvement of $5-\mathrm{HT}_{2 \mathrm{C}}$ receptors in augmentation of $[\mathrm{DA}]_{\mathrm{ex}}$ and $[\mathrm{NE}]_{\mathrm{ex}}$ in PFC by the olanzapine and fluoxetine combination treatment.

Our current observations have provided a neurochemical hypothesis for the antidepressant effect in TRD patients observed in the recent olanzapine plus fluoxetine clinical trial (Tohen et al. 1999). Olanzapine has been shown to produce significantly greater improvement in mood than haloperidol among patients with comorbid mood disorders and schizophrenia (Tollefson et al. 1997) and also appeared effective in psychotic depression (Rothschild et al. 1999). Fluoxetine, on the other hand, has been proved to be efficacious in the treatment of depression due to increased $[5-\mathrm{HT}]_{\mathrm{ex}}$ (for review see Wong et al. 1995). When olanzapine was combined with fluoxetine, the combination therapy not only produced marked improvement over either single treatment alone for TRD, but also resulted in a rapid onset of action (Tohen et al. 1999). A deficiency in brain monoamine systems including that of 5-HT, DA, or NE have long been hypothesized for the pathogenesis of depression, and drugs that enhance 5-HT, DA or NE transmission in brain have been proven to have antidepressant effects (Maes and Meltzer 1995; Schatzberg and Schildkraut 1995; Willner 1995).

The brain region of interest in this study, PFC, plays a pivotal role in mood, arousal, and working memory, as well as integrating sensory input. Furthermore, its malfunction is suggested in the cognitive and emotional defects in affective and psychiatric disorders, such as depression and schizophrenia (Berman and Weinberger 1990; Goldman-Rakic 1996; Weinberger and Berman 1996). Neuroanatomically, the PFC receives rich innervation from 5-HT, DA, and NE pathways originating from cell bodies in the dorsal raphe nucleus (DRN), ventral tegmental area (VTA), and locus coeruleus (LC), respectively. By complex and reciprocal modulations via auto- or hetero-receptors such as

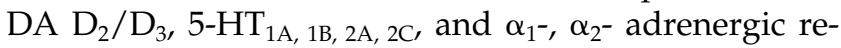
ceptors, the PFC could also modulate the function of temporolimbic cortical and subcortical brain regions involved in mood and affect as well (Maes and Meltzer 1995; Schatzberg and Schildkraut 1995; Willner 1995). Therefore, the persistent, robust increase of extracellular levels of DA, NE as well as similar increases of 5-HT in PFC produced by the combination treatment with 
olanzapine and fluoxetine provides a compelling mechanism for the clinical efficacy of the combination therapy in human TRD trials. In addition, therapy of TRD may require a robust increase of two or more of the monoamines and, thus, the combination therapy may have an additive and more powerful therapeutic effect compared to therapy involving an increase of only one neurotransmitter alone.

\section{REFERENCES}

Amsterdam JD, Hornig-Rohan M (1996): Treatment algorithms in treatment-resistant depression. Psychiatry Clin North Am 19:371-386

Beasley CM Jr, Sanger T, Satterlee W, Tollefson G, Tran P, Hamilton S (1996): Olanzapine versus placebo: Results of a double-blind, fixed-dose olanzapine trial. Psychopharmacology 124:159-167

Berman KF, Weinberger DR (1990): The prefrontal cortex in schizophrenia and other neuropsychiatric diseases: In vivo physiological correlates of cognitive deficits. Prog Brain Res 85:521-537

Bymaster FP, Calligaro DO, Falcone JF, Marsh RD, Moore NA, Tye NC, Seeman P, Wong DT (1996): Radioreceptor binding profile of the atypical antipsychotic olanzapine. Neuropsychopharmacology 14:87-96

Bymaster FP, Rasmussen K, Calligaro DO, Nelson DL, DeLapp NW, Wong DT, Moore NA (1997): In vitro and in vivo biochemistry of olanzapine: A novel, atypical antipsychotic drug. J Clin Psychiatry 58:28-36

Dreshfield LJ, Wong DT, Perry KW, Engleman EA (1996): Enhancement of fluoxetine-dependent increase of extracellular serotonin (5-HT) levels by (-)-pindolol, an antagonist at 5-HT1A receptors. Neurochem Res 21:557-562

Gobert A, Rivet JM, Cistarelli JM, Millan MJ (1997): Buspirone enhances duloxetine- and fluoxetine-induced increases in dialysate levels of dopamine and noradrenaline, but not serotonin, in the frontal cortex of freely moving rats. J Neurochem 68:1326-1329

Goldman-Rakic PS (1996): The prefrontal landscape: Implications of functional architecture for understanding human mentation and the central executive. Philosophical Transactions of the Royal Society of London-Series B. Biol Sci 351:1445-1453

Hertel P, Nomikos GG, Iurlo M, Svensson TH (1996): Risperidone: regional effects in vivo on release and metabolism of dopamine and serotonin in the rat brain. Psychopharmacology 124:74-86

Hertel P, Nomikos GG, Schilstrom B, Arborelius L, Svensson TH (1997): Risperidone dose-dependently increases extracellular concentrations of serotonin in the rat frontal cortex: Role of alpha 2-adrenoceptor antagonism. Neuropsychopharmacology 17:44-55

Heym J, Koe BK (1988): Pharmacology of sertraline: A review. J Clin Psychiatry 49:40-45

Ichikawa J, Kuroki T, Dai J, Meltzer HY (1998): Effect of antipsychotic drugs on extracellular serotonin levels in rat medial prefrontal cortex and nucleus accumbens. Eur J Pharmacol 351:163-171
Kessler RC, McGonagle KA, Zhao S, Nelson CB, Hughes M, Eshleman S, Wittchen HU, Kendler KS (1994): Lifetime and 12-month prevalence of DSM-III-R psychiatric disorders in the United States. Results from the National Comorbidity Survey. Arch Gen Psychiatry 51: 8-19

Koe BK, Weissman A, Welch WM, Browne RG (1983): Sertraline, 1S,4S-N-methyl-4-(3,4-dichlorophenyl)-1,2,3,4tetrahydro-1-naphthylamine, a new uptake inhibitor with selectivity for serotonin. J Pharmacol Exp Ther 226:686-700

Kuroki T, Meltzer HY, Ichikawa J (1999): Effects of antipsychotic drugs on extracellular dopamine levels in rat medial prefrontal cortex and nucleus accumbens. J Pharmacol Exp Ther 288:774-781

Li XM, Perry KW, Wong DT, Bymaster FP (1998): Olanzapine increases in vivo dopamine and norepinephrine release in rat prefrontal cortex, nucleus accumbens and striatum. Psychopharmacology 136:153-161

Maes M, Meltzer HY (1995): The serotonin hypothesis of major depression. In Bloom FE, Kupfer DJ (eds), Psychopharmacology: The Fourth Generation of Progress. New York, NY, Raven Press Ltd, pp 933-944

Millan MJ, Dekeyne A, Gobert A (1998): Serotonin (5-HT)2C receptors tonically inhibit dopamine (DA) and noradrenaline (NA), but not 5-HT, release in the frontal cortex in vivo. Neuropharmacology 37:953-955

Nelson JC (1998): Treatment of antidepressant nonresponders: Augmentation or switch? J Clin Psychiatry 59:35-41

Nierenberg AA, Amsterdam JD (1990): Treatment-resistant depression: Definition and treatment approaches. J Clin Psychiatry 51:39-47

Palvimaki EP, Roth BL, Majasuo H, Laakso A, Kuoppamaki M, Syvalahti E, Hietala J (1996): Interactions of selective serotonin reuptake inhibitors with the serotonin 5-HT2c receptor. Psychopharmacology 126:234-240

Paxinos G, Watson C (1986): The Rat Brain in Stereotaxic Coordinates. San Diego, CA, Academic Press

Perry KW, Fuller RW (1992): Effect of fluoxetine on serotonin and dopamine concentration in microdialysis fluid from rat striatum. Life Sci 50:1683-1690

Perry KW, Fuller RW (1997): Fluoxetine increases norepinephrine release in rat hypothalamus as measured by tissue levels of MHPG-SO 4 and microdialysis in conscious rats. J Neural Transm 104:953-966

Pessia M, Jiang ZG, North RA, Johnson SW (1994): Actions of 5-hydroxytryptamine on ventral tegmental area neurons of the rat in vitro. Brain Res 654:324-330

Roose SP, Glassman AH, Walsh BT, Woodring S (1986): Tricyclic nonresponders: Phenomenology and treatment. Am J Psychiatry 143:345-348

Rothschild AJ, Bates KS, Boehringer KL, Syed A (1999): Olanzapine response in psychotic depression. J Clin Psychiatry 60:116-118

Schatzberg AF, Schildkraut J (1995): Recent studies on norepinephrine systems in mood disorders. In Bloom FE, Kupfer DJ (eds), Psychopharmacology: The Fourth Generation of Progress. New York, NY, Raven Press Ltd, pp 911-920

Schmidt CJ, Fadayel GM (1995): The selective 5-HT2A receptor antagonist, MDL 100,907, increases dopamine efflux in the prefrontal cortex of the rat. Eur J Pharmacol 273:273-279 
Schotte A, Janssen PF, Gommeren W, Luyten WH, Van Gompel P, Lesage AS, De Loore K, Leysen JE (1996): Risperidone compared with new and reference antipsychotic drugs: In vitro and in vivo receptor binding. Psychopharmacology 124:57-73

Sorensen SM, Kehne JH, Fadayel GM, Humphreys TM, Ketteler HJ, Sullivan CK, Taylor VL, Schmidt CJ (1993): Characterization of the 5-HT2 receptor antagonist MDL 100907 as a putative atypical antipsychotic: Behavioral, electrophysiological and neurochemical studies. J Pharmacol Exp Ther 266:684-91

Sprouse J, Clarke T, Reynolds L, Heym J, Rollema H (1996): Comparison of the effects of sertraline and its metabolite desmethylsertraline on blockade of central 5-HT reuptake in vivo. Neuropsychopharmacology 14:225231

Thase ME, Rush AJ (1995): Treatment-resistant depression. In Bloom FE, Kupfler DJ (eds), Psychopharmacology: The Fourth Generation of Progress. New York, NY, Raven Press, pp 1081-1097

Thomas DN, Nutt DJ, Holman RB (1998): Sertraline, a selective serotonin reuptake inhibitor modulates extracellular noradrenaline in the rat frontal cortex. J Psychopharmacol 12:366-370

Tohen M, Shelton R, Tollefson GD, Stahl S, Jacobs T, Gannon KS (1999): Olanzapine plus fluoxetine: Double-blind and open-label results in treatment-resistant major depressive disorder. 12th European College of Neuropsychopharmacology Congress (ECNP), London, UK, September 21-25, 1999

Tollefson GD, Beasley CM Jr, Tran PV, Street JS, Krueger JA, Tamura RN, Graffeo KA, Thieme ME (1997): Olanzapine versus haloperidol in the treatment of schizophrenia and schizoaffective and schizophreniform disorders: Results of an international collaborative trial. Am J Psychiatry 154:457-465

Tollefson GD, Sanger TM, Lu Y, Thieme ME (1998): Depressive signs and symptoms in schizophrenia: A prospec- tive blinded trial of olanzapine and haloperidol [published erratum appears in Arch Gen Psychiatry 1998; 55(11):1052]. Arch Gen Psychiatry 55:250-258

Volonte M, Monferini E, Cerutti M, Fodritto F, Borsini F (1997): BIMG 80, a novel potential antipsychotic drug: Evidence for multireceptor actions and preferential release of dopamine in prefrontal cortex. J Neurochem 69:182-190

Weinberger DR, Berman KF (1996): Prefrontal function in schizophrenia: Confounds and controversies. Philosophical Transactions of the Royal Society of LondonSeries B. Biol Sci 351:1495-1503

Westerink BH, de Boer P, de Vries JB, Kruse CG, Long SK (1998): Antipsychotic drugs induce similar effects on the release of dopamine and noradrenaline in the medial prefrontal cortex of the rat brain. Eur J Pharmacol 361:27-33

Willner P (1995): Dopaminergic mechanism in depression and mania. In Bloom FE, Kupfer DJ (eds), Psychopharmacology: The Fourth Generation of Progress. New York, NY, Raven Press, pp 921-931

Wong DT, Bymaster FP, Engleman EA (1995): Prozac (fluoxetine, Lilly 110140), the first selective serotonin uptake inhibitor and an antidepressant drug: Twenty years since its first publication. Life Sci 57:411-441

Wong DT, Bymaster FP, Reid LR, Threlkeld PG (1983): Fluoxetine and two other serotonin uptake inhibitors without affinity for neuronal receptors. Biochem Pharmacol 32:1287-1293

Wong DT, Threlkeld PG, Robertson DW (1991): Affinities of fluoxetine, its enantiomers, and other inhibitors of serotonin uptake for subtypes of serotonin receptors. Neuropsychopharmacology 5:43-47

Zhang W, Bymaster FP (1999): The in vivo effects of olanzapine and other antipsychotic agents on receptor occupancy and antagonism of dopamine D1, D2, D3, 5HT2A and muscarinic receptors. Psychopharmacology 141: 267-278 